\title{
Fatores que influenciam na percepção das competências para o exercício da docência
}

\author{
Vânia Maria Jorge Nassif \\ Universidade Presbiteriana Mackenzie, Centro de Ciências Sociais e Aplicadas Faculdade Campo Limpo Paulista
}

\author{
Darcy Mitiko Mori Hanashiro \\ Universidade Presbiteriana Mackenzie, Centro de Ciências Sociais e Aplicadas
}

\author{
Rosane Rivera Torres \\ Universidade de São Paulo, Escola de Artes, Ciências e Humanidades
}

\section{Introdução}

O século XXI está apenas começando, mas apresenta características marcantes do século passado que, por sua vez, foi palco de grandes desafios para as organizações de sucesso. Na medida em que o mundo dos negócios se foi estreitando e se tornando interligado, as exigências ficaram mais complexas e dinâmicas, levando pessoas e organizações a um nível de reflexão sem precedentes acerca das competências necessárias à sobrevivência num mercado competitivo. Se uma organização possuir recursos e capacidades superiores aos de seus concorrentes e adotar estratégia que utilize esses recursos e capacidades de maneira eficaz, ela poderá criar vantagens. Há consenso de que o conhecimento e o aprendizado são essenciais para todas as organizações num ambiente competitivo e gerador de grandes transformações. É interessante analisar o parentesco semântico existente entre as ideias de competência e de competitividade. A origem comum é o verbo competir (com+petere), que em latim significa "buscar com, esforçar-se com ou pedir com". Quando se disputa um bem material juntamente com alguém, torna-se natural o caráter mutuamente exclusivo da conquista: para alguém ganhar, alguém deve perder. Em contrapartida, o mesmo não necessita ocorrer quando o bem que se disputa, ou que se busca com alguém, é o conhecimento. Pode-se dar ou vender o conhecimento que se tem sem precisar ficar sem ele, pois o conhecimento não é um bem fungível, não se gasta: quanto mais usamos, mais novo ele fica. Isso acarreta necessariamente uma ampliação no significado original da competição, da competência no sentido de "buscar com".

A busca dessa compreensão deveria ser fórum de discussões nos mais variados ambientes organizacionais, e isso não pode ocorrer de maneira diferente no contexto das instituições de ensino superior, local de construção e promoção do saber. As universidades representam um segmento importante no contexto econômico e social e têm parcela de responsabilidade pelos profissionais que colocam no mercado de trabalho. O lado humano, sobretudo, o professor, tem sido pouco valorizado no contexto universitário, embora ele seja o maior responsável pela obtenção de resultados. É nesse sentido que o professor uni- 
versitário se constitui em um eixo fundamental na cadeia de valores do ensino, o processo envolvendo o conjunto de atividades que vão desde o aluno até o mercado, suprindo com força de trabalho capacitada os novos desafios de competitividade. Portanto, é necessário as universidades adequarem-se às novas exigências globais, reconhecerem que produtividade e qualidade se constituem na marca distintiva para sua competitividade e, em que pese o avanço tecnológico, o ser humano é o grande diferencial nas organizações triunfadoras. Smith (1997) afirma que só as pessoas mudam habilidades, comportamentos e relacionamentos, e somente o fazem em seu trabalho real.

O perfil de qualquer profissional que pretenda manter-se atualizado é o de empreendedor, um profissional competente em sua área, com visão das questões gerais da sociedade que cerca a sua instituição e a si mesmo, aberto ao novo e com poder de tomada de decisões rápidas e seguras. Acima de tudo, um indivíduo aberto ao aprendizado constante, atento à sua capacidade de transmissão do conhecimento, habilidoso nas críticas e preparado para contextualizar as relações socioculturais e possuidor de uma desenvoltura investigatória aguçada (Vasconcelos, 1996). Do professor cobra-se a necessidade de formar alunos capacitados para enfrentar as exigências de mercado, sem, contudo, haver reflexão mais profunda sobre quais são e como esses professores desenvolvem suas competências. Não obstante as instituições de ensino superior (IES) estejam implementando novas modalidades de ensino, a exemplo do ensino a distância e/ ou por meio de instrumentos assistidos por tecnologia computacional, não se tem verificado preocupação, por parte dessas IES, em desenvolver competências para que os professores possam atuar nesse novo ambiente de ensino. Morgado (2001) reforça que a chave do sucesso dessas modalidades ainda continua sendo o professor, que, além do papel pedagógico, deve desenvolver competências de gestão, social e técnica. Dessa forma, o papel do docente nesse contexto é fundamental, e as escolas necessitam de profissionais dispostos a enfrentar essas mudanças, a assumir riscos e se adequar ao perfil de um profissional competente, criativo, sensível, motivado e engajado nas relações interpessoais.

Dessa forma, o objetivo geral da pesquisa da qual originou este artigo foi analisar se a percepção de competências requeridas para o exercício da docência e as variáveis de caracterização estão relacionadas a grupos específicos (clusters) de professores universitários de instituições privadas do estado de São Paulo. Além deste, pontuam-se os seguintes objetivos específicos: identificar domínios conceituais da escala (questionário) e identificar clusters de professores e analisá-los quanto às variáveis de caracterização e quanto aos domínios conceituais da escala.

Acredita-se que os resultados encontrados neste estudo sejam de grande relevância para as universidades, mostrando quais são as competências requeridas pelos docentes e como estes percebem de forma diferente essas competências de acordo com algumas de suas características ocupacionais e pessoais. Além desses resultados direcionados ao ensino (identificação das competências necessárias à docência), este artigo poderá trazer contribuição, do ponto de vista metodológico, ao discutir fatores determinantes da percepção de competências entre professores universitários.

\section{O ensino superior e o ser professor}

A massificação do ensino em geral e do superior, especificamente, tem trazido uma nova realidade para as IES. Essa situação tem provocado mudanças estruturais, sociais e políticas e procura resgatar necessidades básicas para a qualidade do ensino e formação de cidadãos. Elas estão respaldadas em políticas instituídas por ações governamentais e em pesquisa nas instituições, sobretudo particulares, permitindo assim uma análise diagnóstica de áreas críticas do sistema. Sampaio (1998) pontua que o ensino privado no Brasil expandiu e ampliou suas atividades em todas as regiões do país, sendo o estado de São Paulo responsável por $82 \%$ do total desse crescimento. A autora avalia que este ocorreu de maneira desordenada, assumindo caráter mercantilista, distanciando-se, cada vez mais, da qualidade de ensino e pesquisa gerada pelo setor de ensino público. 
Com as exigências pregoadas pelos órgãos oficiais no sentido de reverter esse quadro e impulsionar a educação para a melhoria da qualidade, fica claro que é preciso repensar os papéis e as funções do ensino superior. Além disso, torna relevante o papel dos educadores e dos procedimentos acadêmicos e administrativos em função do crescimento e da importância que a educação tem no mercado de trabalho.

No Brasil, as universidades particulares apresentam características distintas em relação às públicas, tanto no sistema de gestão de recursos humanos (as públicas se pautam por um plano de carreira, regime de trabalho integral e parcial, titulação) como também na produção do conhecimento por meio da pesquisa, dos avanços tecnológicos e dos serviços prestados à comunidade. Esses aspectos ainda se mostram incipientes nas instituições particulares.

$\mathrm{Na}$ virada do século, os modelos que tradicionalmente informaram a qualidade do ensino superior no mundo parecem fazer água. Segundo Balbachevsk (1999), a formação humanista, voltada para o desenvolvimento de um conhecimento enciclopédico e erudito, parece fracassar na medida em que não dota o aluno das ferramentas básicas para lidar com uma realidade profissional em mutação, em que credenciais adquiridas são, por si sós, cada vez menos importantes. Além do mais, a formação clássica do pesquisador, dentro de uma tradição disciplinar específica e tendendo para um padrão cada vez mais especializado, padece de fraquezas semelhantes. No entender de especialistas no assunto, os alunos formados dentro dessa perspectiva carecem de flexibilidade suficiente para enfrentar alternativas de carreira profissional, para trabalhar em contextos multidisciplinares.

Thurler (2002) afirmam que, ao fazer um inventário das modalidades de desenvolvimento profissional à disposição dos professores, se depara com duas situações: primeiro, a disponibilidade do professor para se aventurar em novas condutas e adquirir novas competências, naturalmente mais exigentes; segundo, a vontade de as autoridades escolares e políticas de diversificar e de reconhecer as alternativas possíveis, investindo nos recursos necessários e importantes para subsidiar a ação do professor.

Sob essas considerações, o professor tem-se mostrado figura importante e determinante no êxito ou fracasso do processo educativo no contexto da universidade. Sobre ele recai grande responsabilidade quanto aos resultados esperados, sobretudo no que diz respeito à formação de profissionais que atuam no mercado de trabalho. A aceitação das regras do jogo institucional torna-o cúmplice na responsabilidade sobre os resultados finais, pois, para ensinar, não é suficiente conhecer a ciência e seus conteúdos, é preciso saber o que seja educação e como se configura quanto ao homem a educar e quanto ao projeto de uma sociedade justa e desenvolvida (Niskier, 1998).

Ensinar é um trabalho de reflexão crítica em que se analisam o ensino e a aprendizagem como tais. Assim, a capacitação e a qualificação dos professores frequentemente têm emergido como palavra de ordem. A ênfase recai na necessidade de o profissional rever e desenvolver as competências para acompanhar a demanda de informações, atentar para a introdução de novas tecnologias, estar presente e fazer parte do mundo dos jovens e ser parte integrante do processo de mudança instalado no setor educacional. As universidades, segundo Vasconcelos (1996), têm buscado professores cujo perfil é o do empreendedor aberto ao aprendizado constante, atento à sua capacidade de transmissão do conhecimento, habilidoso nas críticas e contextualizações das relações socioculturais e com desenvoltura investigatória aguçada.

Assim, este ser educador necessita de flexibilidade para acompanhar as mudanças na educação, na sociedade, na ciência e, consequentemente, no ensino superior, de forma que promova um ensino de qualidade para o saber fazer, o saber pensar, o saber ser. Kincheloe (1997) intitula essas proezas de competências requeridas pelos novos tempos. Pontua que elas levam a questionamentos, interpretações e flexibilidade intelectual, chamando-as de atos cognitivos essenciais. É essencial que se crie a mentalidade do aprender a aprender e se compreenda que ensinar exige método, pesquisa, ética e criticidade num ambiente de riscos e 
oportunidades. Fica evidente, também, que os conhecimentos, as competências e as habilidades exigidas pelo mercado de trabalho mudam constantemente.

A universidade precisa preparar-se para acompanhar e reorganizar-se com base na concepção de conhecimento, operando com teorias de aprendizagem e formas de organização do ensino que superem as práticas pedagógicas tradicionalmente centradas na memorização e na reprodução de informações ou no treinamento para saber fazer, já que a demanda que hoje se coloca é pela formação de cidadãos pensantes e criativos.

Dentro desse argumento, é preciso esclarecer que o trabalho e a atividade do professor não serão suficientes para mudar o mundo. Não pode ser idealizada a tarefa educacional, mas é preciso reconhecer que, ao fazer alguma coisa dentro do espaço da instituição, o professor pode trazer boas contribuições.

Para Shor e Freire (1986), o professor precisa desenvolver sua humildade, esclarecer que é preciso reaprender o que acha que já sabe. Também se faz necessário aguçar seu senso crítico a respeito de como a sociedade funciona, para entender como a educação funciona no contexto global e no contexto da sala de aula, sendo um erro separar a dinâmica global da mudança social e da prática educacional.

\section{A escola e a competência docente}

A ideia de que a meta principal da escola não é o ensino dos conteúdos disciplinares, mas sim o desenvolvimento das competências pessoais, está hoje no centro das atenções. Trata-se de uma questão com raízes bastante profundas, que se presta a um grande número de mal-entendidos.

Machado (2002) investiga essas raízes e traz à luz referências desde Trivium, currículo básico na Grécia clássica, composto pelas disciplinas de lógica, gramática e retórica, que certamente não visava à formação de lógicos ou linguistas, mas a formação de cidadão, pois nunca tiveram conceitualmente o status de fim em si mesmas. Trivium desempenhou um duplo papel: o de mediação entre o conhecimento em sentido pleno e aquilo que deveria ser ensinado aos indivíduos em formação e o de meio para o desenvolvimento pessoal, para a formação do caráter, para a construção da cidadania. Ele não visava a qualquer formação específica ou à preparação para o trabalho.

A partir da segunda metade do século XIX, conforme declara Machado (idem), ocorre certo descolamento entre o conhecimento chamado científico (o que rigorosamente seria um pleonasmo vicioso) e o conhecimento em sentido amplo, com consequente superestimação de uma forma de conhecer, a científica. Aos poucos, diz o autor, o processo de fragmentação do conhecimento caminhou no sentido da crescente subdivisão da própria ciência em múltiplas disciplinas e supervalorização do conhecimento disciplinar.

Há décadas que a escola se organiza como se os objetivos da educação derivassem daqueles que caracterizam o desenvolvimento das ciências, sendo eles decorrentes da busca do desenvolvimento das diversas disciplinas científicas. Hoje, parece mais claro que o desenvolvimento científico não pode ser considerado de forma desvinculada do projeto a que serve, que ele se realiza em um cenário de valores socialmente acordados. A ciência precisa servir às pessoas; ao mesmo tempo, a organização da escola deve visar ao desenvolvimento das competências pessoais.

O senso comum entende a semântica da palavra competência como: as pessoas é que são ou não competentes, e toda tentativa de atribuição de competência a objetos e artefatos parece insólita ou inadequada.

No contexto educacional, Machado (idem) discute que a noção de competência é fecunda e abrangente, tendo em vista o conceito de pessoalidade, pois é esta a primeira característica da ideia de competência. Conhecer é entender o significado e o significado é sempre construído pelas pessoas. Outro elemento que caracteriza a ideia de competência é o âmbito no qual ela se exerce. Segundo o autor, não existe competência sem referência a um contexto no qual ela se materializa. O terceiro elemento fundamental é a mobilização, pois uma competência deve estar sempre associada à mobilização de saberes. 
Não se trata de um conhecimento acumulado, mas da virtualização de uma ação, da capacidade de recorrer ao que se sabe para realizar o que se deseja e o que se projeta.

Esse conceito tem pertinência no contexto na literatura administrativa, já que as empresas que buscam competitividade têm adotado posturas de aprendizagem intensiva e permanente, enquanto buscam a identificação de estratégias que maximizem a probabilidade de sobreviver e prosperar. Nesse sentido, Fleury e Fleury (2000) definem competência como um saber agir responsável e reconhecido, que implica mobilizar, integrar, transferir conhecimentos, recursos, habilidades, que agreguem valor econômico à organização e valor social ao indivíduo.

E como falar da competência de professores nesse contexto de grande competitividade, em que prevalece a valorização da titulação em detrimento do saber?

Por um lado, observa-se com clareza, entre os professores, um movimento de busca por titulação, dadas as exigências dos órgãos oficiais, das instituições e do mercado de trabalho. Por parte das instituições de ensino superior, prevalece a busca de professores titulados, a fim de atender às exigências de credenciamento dos cursos em vários níveis. Entretanto, Perrenoud (2000) afirma que, considerada a diversidade de problemas com os quais o professor é confrontado em sala de aula, pode avaliar-se que as competências a que recorre começaram a ser construídas bem antes de ele decidir tornar-se professor. Afirma que as experiências de vida podem ser uma preparação sem que o interessado tenha consciência disso e muito antes de saber que se tornará professor. Essa tomada de consciência de certas competências como, por exemplo, capacidade de compartilhar seu saber, de explicar fenômenos complexos, de comunicar, de seduzir, de influenciar - condiciona a orientação para o ensino.

Esses argumentos nos remetem à questão: Quais são as competências necessárias para o exercício da docência?

As respostas a essa pergunta não são fáceis de serem respondidas. Entretanto, diversos autores re- nomados pontuam essas competências conforme a síntese elaborada no Quadro 1.

Quadro 1: Referências sobre competência de docentes

\begin{tabular}{|c|c|}
\hline Autores/anos & Ideias de competência \\
\hline Altet (2001) & $\begin{array}{l}\text { Buscar constantemente conhecimentos, } \\
\text { savoir-faire e postura; ações e atitudes } \\
\text { para o exercício da profissão; saber ana- } \\
\text { lisar, saber refletir e saber justificar. }\end{array}$ \\
\hline $\begin{array}{l}\text { Baillauquès } \\
\text { (2001) }\end{array}$ & $\begin{array}{l}\text { Ser reflexivo, capaz de avaliação e au- } \\
\text { toavaliação; atitude crítica e de tomada } \\
\text { de decisão; aprender sempre. }\end{array}$ \\
\hline Bélair (2001) & $\begin{array}{l}\text { Ter como eixo de suas ações o aprendi- } \\
\text { zado para colaborar na transformação } \\
\text { do aluno. }\end{array}$ \\
\hline Castanho (2000) & $\begin{array}{l}\text { Buscar ação interdisciplinar para esti- } \\
\text { mular a criticidade e integrar ensino } \\
\text { com pesquisa. }\end{array}$ \\
\hline Charlier (2001) & $\begin{array}{l}\text { Priorizar três elementos indissociáveis: } \\
\text { projetos-atos-competências; saberes, } \\
\text { representações, teorias pessoais e } \\
\text { esquemas de ação mobilizados para } \\
\text { resolver problemas. }\end{array}$ \\
\hline $\begin{array}{l}\text { D'Ambrósio } \\
(1995)\end{array}$ & $\begin{array}{l}\text { Ser visionário sem perder o contexto } \\
\text { em que está inserido. }\end{array}$ \\
\hline De Sordi (2000) & $\begin{array}{l}\text { Construir condições favoráveis para que } \\
\text { a aprendizagem aconteça. }\end{array}$ \\
\hline Dutra (2001) & $\begin{array}{l}\text { Capacidade de entrega da pessoa; } \\
\text { conjunto de qualificações que a pessoa } \\
\text { possui para entregar. }\end{array}$ \\
\hline Faingold (2001) & $\begin{array}{l}\text { Pronto para tratar a informação durante } \\
\text { a ação que lhe permita improvisar res- } \\
\text { postas aos diferentes imprevistos. }\end{array}$ \\
\hline Freire (1997) & $\begin{array}{l}\text { Necessita de método, pesquisa, ética } \\
\text { e criatividade; aberto à produção do } \\
\text { conhecimento; bom senso, humilda- } \\
\text { de, apreensão da realidade, alegria e } \\
\text { esperança. }\end{array}$ \\
\hline Hass (1998) & $\begin{array}{l}\text { Preparar os alunos contra os perigos da } \\
\text { fragmentação; construir uma identidade } \\
\text { mais integrada; ser teórico-prático; res- } \\
\text { ponder às questões pessoais e sociais. }\end{array}$ \\
\hline $\begin{array}{l}\text { Kincheloe } \\
(1997)\end{array}$ & $\begin{array}{l}\text { O saber, o saber fazer, o saber ser e o } \\
\text { saber conviver; questionamentos, inter- } \\
\text { pretações e flexibilidade intelectual. }\end{array}$ \\
\hline Kullok (1998) & $\begin{array}{l}\text { Recuperar o entusiasmo, uma série de } \\
\text { atitudes, crença, valores e habilidades } \\
\text { que se perderam ao longo do tempo e } \\
\text { que constituem a essência do educador. }\end{array}$ \\
\hline
\end{tabular}

(continua) 
(continuação)

\begin{tabular}{|c|c|}
\hline Masetto (2001) & $\begin{array}{l}\text { Passar de professor "ensinante" para } \\
\text { professor "que está com" o aluno, para } \\
\text { que ele possa aprender. }\end{array}$ \\
\hline Moraes (1997) & $\begin{array}{l}\text { Incorporar a criatividade e a comunica- } \\
\text { ção para interpretar a realidade; flexibi- } \\
\text { lidade para acompanhar as mudanças; } \\
\text { promover um ensino de qualidade para } \\
\text { o saber fazer, para o saber pensar, para } \\
\text { o saber ser, criando a mentalidade do } \\
\text { aprender a aprender. }\end{array}$ \\
\hline Niskier (1998 ) & $\begin{array}{l}\text { Um homem do saber, um artista, e não } \\
\text { um tecnocrata. }\end{array}$ \\
\hline $\begin{array}{l}\text { Paquay (2001) e } \\
\text { Wagner (1988) }\end{array}$ & $\begin{array}{l}\text { Antes de tudo é uma pessoa em evolu- } \\
\text { ção e em busca de um "torna-se" uma } \\
\text { pessoa em relação ao outro. }\end{array}$ \\
\hline $\begin{array}{l}\text { Perrenoud } \\
(2000)\end{array}$ & $\begin{array}{l}\text { Organizar e dirigir situações de apren- } \\
\text { dizagem; administrar suas progressões; } \\
\text { conceber e fazer evoluir os dispositivos } \\
\text { de diferenciação; envolver alunos; tra- } \\
\text { balhar em equipe; utilizar novas tecno- } \\
\text { logias; enfrentar deveres e dilemas éti- } \\
\text { cos; administrar a própria formação. }\end{array}$ \\
\hline $\begin{array}{l}\text { Pimentel apud } \\
\text { Kullok (1998) }\end{array}$ & $\begin{array}{l}\text { Questionador, flexível à mudança, in- } \\
\text { ventor, facilidade para modificar, sentir, } \\
\text { participar, arriscar, inovar. }\end{array}$ \\
\hline Scoz (1996) & $\begin{array}{l}\text { Auxiliar a descobrir e a se apropriar } \\
\text { dos conhecimentos necessários para } \\
\text { uma ação consciente no mundo; visão } \\
\text { interdisciplinar. }\end{array}$ \\
\hline $\begin{array}{l}\text { Shore Freire, } \\
\text { (1986) }\end{array}$ & $\begin{array}{l}\text { Ter humildade; reaprender o que } \\
\text { acha que já sabe; desenvolver o senso } \\
\text { crítico. }\end{array}$ \\
\hline Thurler (2002) & $\begin{array}{l}\text { Traduzir os objetivos em dispositivos } \\
\text { de aprendizagem; observar a progres- } \\
\text { são do aluno; flexibilidade; dosar os } \\
\text { desafios em função das competências } \\
\text { individuais; dominar recursos; assumir } \\
\text { os resultados. }\end{array}$ \\
\hline $\begin{array}{l}\text { Tramontin } \\
(1998)\end{array}$ & $\begin{array}{l}\text { Corresponsável e cúmplice juntamente } \\
\text { com a IES sobre resultados finais; cará- } \\
\text { ter e dignidade. }\end{array}$ \\
\hline $\begin{array}{l}\text { Vasconcelos } \\
(1996)\end{array}$ & $\begin{array}{l}\text { Transmissor de conhecimento, saber } \\
\text { ensinar; ser crítico; bom pesquisador; } \\
\text { capacitado a produzir e a abrir-se ao } \\
\text { novo e induzir seu aluno a criar. }\end{array}$ \\
\hline
\end{tabular}

Fonte: Organizado pelas autoras.

Para ter êxito nessa difícil e delicada operação que é a arte de ensinar, torna-se primordial que os professores sejam vistos como pessoas e profissionais capazes de contribuir e colaborar na transformação do aluno em agente de aprendizagem, tendo, como suporte, subsídios institucionais facilitadores dessa tarefa.

Trata-se de um desafio olhar para esse conjunto de competências docentes necessárias e esperadas como resposta do professor diante de seu ofício. Além disso, significa que eles precisarão não apenas reinventar práticas pedagógicas como também cuidar de suas relações interpessoais e profissionais.

\section{A pesquisa em questão}

A pesquisa que deu origem a este artigo se caracteriza primordialmente por ser um estudo do tipo descritivo, cujos propósitos estão relacionados com a verificação de hipóteses e descrição de relações quantitativas entre variáveis especificadas (Tripodi, Fellin \& Mayer, 1981).

Foi realizada a priori uma pesquisa exploratória utilizando entrevistas em profundidade com cinco reitores e quatro profissionais de recursos humanos de instituições de ensino superior particulares do estado de São Paulo, com status de universidade. Com isso, objetivou-se identificar o conceito de competitividade (para as universidades) desses profissionais e as competências requeridas para a docência.

Com base na pesquisa exploratória, foi construído um questionário composto por 60 itens sobre a percepção das competências e informações sobre apoio institucional. Utilizou-se uma escala do tipo Likert de 6 pontos.

Além dos itens, foram levantadas as seguintes variáveis de caracterização: sexo, estado civil, titulação (pós-doutor, doutor, doutorando, mestre, mestrando e especialista), regime de trabalho (integral, parcial e horista), função (apenas docente, docente/administrativo e docente/outra função), idade, tempo de instituição e tempo de docência.

Esse instrumento passou por vários tratamentos estatísticos para avaliação da consistência interna e validade, processos estes que serão apresentados na parte de análises dos resultados.

Esta pesquisa teve como universo inicial 21 instituições de ensino superior particulares do estado de São Paulo, com status de universidade. Destas, cinco 
aceitaram participar da pesquisa. Foram enviados 1.500 questionários para professores de diferentes áreas do conhecimento, definidos como populaçãoalvo deste estudo; deles, 282 retornaram, perfazendo $18,8 \%$ da população considerada amostra deste estudo.

O primeiro passo, referente ao tratamento dos dados, iniciou-se pela análise fatorial, a partir da qual dedicou-se uma análise de confiabilidade do instrumento, sua validação e a análise das correlações entre os escores da escala, as variáveis de caracterização dos respondentes e os clusters. Tendo em vista os objetivos da pesquisa, foram utilizadas as seguintes técnicas de análise de dados: análise fatorial, estatística descritiva simples, análise de correlação (Spearman), análise de conglomerados (clusters), teste qui-quadrado de associação, teste U de Mann-Withney e regressão logística.

\section{Apresentação da escala}

Realizou-se análise fatorial pelo método de rotação ortogonal (varimax). Dessa fatorial eliminaram-se 14 variáveis (restando 46 da escala original), cujos valores da diagonal principal (measures of sampling adequacy) da matriz de correlação "anti-imagem" se situaram abaixo de 0,7 (Hair et al., 2005, p. 99). Uma segunda fatorial foi aplicada, resultando em 12 fatores, com variância total explicada de 59,31\% e eigenvalues acima de 1, conforme apresentado na Tabela 1 .

Tabela 1: Fatores e variância

\begin{tabular}{|c|l|c|c|}
\hline \multicolumn{2}{|c|}{ Fatores } & $\%$ & $\begin{array}{c}\% \text { Acu- } \\
\text { mulado }\end{array}$ \\
\hline 1 & Apoio institucional & 8,907 & 8,907 \\
\hline 2 & Habilidade interpessoal & 8,707 & 17,615 \\
\hline 3 & Capacidade didático-pedagógica & 6,189 & 23,803 \\
\hline 4 & Abertura à inovação & 5,974 & 29,777 \\
\hline 5 & Características sociáveis & 4,330 & 34,106 \\
\hline 6 & $\begin{array}{l}\text { Contribuição para o } \\
\text { desenvolvimento do aluno }\end{array}$ & 4,075 & 38,181 \\
\hline 7 & Titulação & 4,006 & 42,188 \\
\hline 8 & $\begin{array}{l}\text { Uso diferenciado de métodos de } \\
\text { avaliação }\end{array}$ & 3,731 & 45,919 \\
\hline 9 & Autoaprendizado & 3,725 & 49,644 \\
\hline 10 & Elaboração teórica & 3,531 & 53,175 \\
\hline 11 & Afabilidade & 3,137 & 56,311 \\
\hline 12 & Recursos técnicos & 3,001 & 59,313 \\
\hline
\end{tabular}

Fonte: Dados extraídos da pesquisa.
A validade de um instrumento é uma importante característica para avaliar a sua efetividade (Richardson, 1999). Um instrumento é válido se ele mede o que se deseja, e, para tal, deve ser confiável. A confiabilidade, também conhecida por fidedignidade (Kerlinger, 1980), refere-se à regularidade, exatidão, precisão e estabilidade do instrumento. Coeficientes de fidedignidade ou de consistência interna são representados por um valor que varia entre zero e um, refletindo a estabilidade ou consistência das medições obtidas por meio de determinado instrumento (Richardson, 1999).

Tabela 2: Domínio 1 - Apoio institucional

\begin{tabular}{|c|c|}
\hline Itens & $\begin{array}{l}\text { Carga } \\
\text { fatorial }\end{array}$ \\
\hline $\begin{array}{l}\text { A universidade colabora com o } \\
\text { desenvolvimento profissional dos } \\
\text { professores por meio de programas } \\
\text { internos de capacitação. }\end{array}$ & 0,761 \\
\hline $\begin{array}{l}\text { A atividade de pesquisa tem ampliado } \\
\text { a oportunidade de crescimento e } \\
\text { desenvolvimento do professor dessa } \\
\text { universidade. }\end{array}$ & 0,759 \\
\hline $\begin{array}{l}\text { Os programas de aprimoramento e } \\
\text { desenvolvimento profissional gerenciado } \\
\text { pela área de RH dessa universidade } \\
\text { estimulam os professores a participarem. }\end{array}$ & 0,736 \\
\hline $\begin{array}{l}\text { O salário dessa universidade pago aos } \\
\text { professores é competitivo no mercado de } \\
\text { trabalho. }\end{array}$ & 0,668 \\
\hline $\begin{array}{l}\text { O plano de carreira dessa universidade } \\
\text { estimula-me a crescer. }\end{array}$ & 0,646 \\
\hline $\begin{array}{l}\text { A política de recursos humanos valoriza o } \\
\text { docente na universidade. }\end{array}$ & 0,633 \\
\hline $\begin{array}{l}\text { O ambiente de trabalho e o clima } \\
\text { da universidade são um atrativo } \\
\text { para o professor desenvolver suas } \\
\text { potencialidades. }\end{array}$ & 0,604 \\
\hline $\begin{array}{l}\text { A contratação do corpo docente em } \\
\text { período integral ou parcial diferencia essa } \\
\text { universidade no mercado de trabalho. }\end{array}$ & 0,523 \\
\hline
\end{tabular}

Fonte: Dados extraídos da pesquisa.

Dentre os diferentes métodos de cálculo da confiabilidade, optou-se pelo coeficiente alfa de Cronbach, aplicado ao resultado da análise fatorial (fatores e suas respectivas variáveis). Nessa primeira aplicação, o 
coeficiente alfa foi usado para reconfigurar a disposição dos itens dentro de alguns dos fatores.

Ao avaliar o coeficiente alfa de cada um dos 12 fatores, optou-se por excluir os itens contidos nos fatores $5,6,10,11$ e 12 (Tabela 1), pois esses coeficientes se apresentaram abaixo de 0,40. Para os fatores 7, 8 e 9, por conterem dois ou três itens, buscou-se agrupá-los em um único fator, doravante denominado domínio 5. Ao final, o instrumento de 46 itens passou a configurarse com apenas 34, passando a ser denominado escala, e os cinco fatores de domínios conceituais. As Tabelas 2 a 6 apresentam os resultados da análise fatorial.

O domínio 1, intitulado "Apoio institucional”, expressou a percepção dos professores em relação a esse suporte. As duas primeiras variáveis revelaram que existe uma dimensão de pensamento dos professores que acredita serem os programas internos de capacitação colaboradores de seu desenvolvimento profissional e a atividade de pesquisa um dos recursos para ampliar a sua oportunidade de crescimento e desenvolvimento na instituição. Consideraram ainda que uma forma de estimular os professores ao crescimento e desenvolvimento profissional era participando dos programas de aprimoramento e desenvolvimento promovidos pela área de RH. Denota-se desse resultado que os professores entendem que as políticas e as ações empreendidas colaboraram principalmente para seu desenvolvimento e aprimoramento profissional.

O domínio 2, "Habilidade interpessoal”, agrupa itens em que o professor é sempre focalizado em relação aos alunos. A primeira variável, referente à capacidade de escuta, é vista como uma competência fundamental para o professor interagir com seus alunos. Essa competência, vista sob várias dimensões, possibilita a reflexão crítica acerca de seu desempenho, facilita a troca por meio do feedback, negocia regras na condução de grupos e, quando o professor usa a experiência dos alunos para construir o conhecimento, consegue estimular a aprendizagem. Dessa forma, subentende-se que, quando o professor valoriza essas competências, manifesta seu comprometimento com a educação. Esse fator ressalta as competências fundamentais do docente, sobretudo quando este se abre para o relacionamento interpessoal, ou seja, a troca efetiva entre ele e seu aluno.

Tabela 3: Domínio 2 - Habilidade interpessoal

\begin{tabular}{|l|c|}
\hline \multicolumn{1}{|c|}{ Itens } & $\begin{array}{c}\text { Carga } \\
\text { fatorial }\end{array}$ \\
\hline $\begin{array}{l}\text { A capacidade de escuta e o consequente } \\
\text { feedback são atitudes positivas do docente. }\end{array}$ & 0,720 \\
\hline $\begin{array}{l}\text { O professor que faz uma reflexão crítica } \\
\text { sobre o exercício de sua prática aprimora } \\
\text { seu desempenho quotidianamente. }\end{array}$ & 0,673 \\
\hline $\begin{array}{l}\text { As atividades desenvolvidas em sala } \\
\text { de aula e o os trabalhos de pesquisa } \\
\text { elaborados pelos alunos são enriquecidos } \\
\text { quando o professor dá o feedback. }\end{array}$ & 0,635 \\
\hline $\begin{array}{l}\text { O professor que usa as experiências dos } \\
\text { alunos no processo de construção do } \\
\text { conhecimento estimula a aprendizagem. }\end{array}$ & 0,547 \\
\hline $\begin{array}{l}\text { O comprometimento com a educação } \\
\text { facilita o exercício da docência. }\end{array}$ & 0,538 \\
\hline $\begin{array}{l}\text { A condução do grupo e a capacidade de } \\
\text { negociação de regras permitem maior } \\
\text { envolvimento entre professor e aluno. }\end{array}$ & 0,509 \\
\hline $\begin{array}{l}\text { O professor que procura desenvolver } \\
\text { um método próprio para atender às } \\
\text { necessidades dos alunos proporciona } \\
\text { resultados efetivos de aprendizagem. }\end{array}$ & 0,457 \\
\hline $\begin{array}{l}\text { O planejamento das atividades } \\
\text { pedagógicas feitas pelo professor } \\
\text { proporciona ao aluno uma visão integrada } \\
\text { da disciplina lecionada. }\end{array}$ & 0,378 \\
\hline
\end{tabular}

Fonte: Dados extraídos da pesquisa.

Nesse domínio, “Capacidade didático-pedagógica", os itens estão relacionados com o processo ensinoaprendizagem. Quando esse grupo traz a capacidade de liderança do professor como uma competência à docência (de maior carga fatorial), entende-se que o processo de influenciar mudanças significativas nas atitudes dos alunos pode promover segurança e respeito, dando indícios de melhoria de aprendizagem. Além disso, a organização no preparo das aulas, aliada à didática, pode facilitar o desempenho do professor. E, quando ele age com ética e justiça, consegue fortalecer sua imagem perante os alunos. 
Tabela 4: Domínio 3 - Capacidade didáticopedagógica

\begin{tabular}{|l|c|}
\hline \multicolumn{1}{|c|}{ Itens } & $\begin{array}{c}\text { Carga } \\
\text { fatorial }\end{array}$ \\
\hline $\begin{array}{l}\text { A capacidade de liderança do professor } \\
\text { promove segurança e respeito no aluno. }\end{array}$ & 0,665 \\
\hline $\begin{array}{l}\text { A organização no preparo das aulas facilita } \\
\text { o desempenho do docente durante o } \\
\text { desenvolvimento delas. }\end{array}$ & 0,606 \\
\hline $\begin{array}{l}\text { Para a universidade ser competitiva no } \\
\text { mercado, ela precisa ter convênios e } \\
\text { intercâmbio com outras instituições. }\end{array}$ & 0,573 \\
\hline A didática é essencial à docência. & 0,562 \\
\hline $\begin{array}{l}\text { A ética e o sentido de justiça fortalecem a } \\
\text { imagem do professor para os alunos. }\end{array}$ & 0,537 \\
\hline $\begin{array}{l}\text { O processo ensino-aprendizagem (relação } \\
\text { do ensinar com o aprender) permite ao } \\
\text { professor uma compreensão da dinâmica } \\
\text { do aluno. }\end{array}$ & 0,496 \\
\hline
\end{tabular}

Fonte: Dados extraídos da pesquisa.

Diante desse contexto, os professores valorizam os convênios e intercâmbios com outras instituições como forma de estimular a troca e implementar a aprendizagem. Esse dado concretiza um dos aspectos consagrados pela UNESCO, quando é pontuada como estratégia da educação superior à internacionalização, ou seja, a parceria com entidades educacionais similares. O que define a "Capacidade didático-pedagógica" não se limita à utilização correta de métodos e técnicas que permitam a apreensão do conhecimento pelo aluno, mas a sua dinâmica, de forma que o faça avançar na aprendizagem.

No domínio 4, "Abertura à inovação", saber enfrentar desafios para buscar inovações foi considerada uma competência fundamental para o exercício da docência. Depreende-se desse resultado que os professores entendem que é importante estar aberto para interpretar e contextualizar a realidade como meio de desenvolver a crítica nos alunos.

À luz dessas reflexões, embora com carga fatorial baixa, os professores concordam que o seu entusiasmo, a sua capacidade criativa e de resolver problemas podem facilitar a abertura à inovação e despertar nos alunos o desejo de buscar sua criatividade, confiança nas ações do professor e estimular o processo ensinoaprendizagem.

Tabela 5: Domínio 4 - Abertura à inovação

\begin{tabular}{|l|c|}
\hline \multicolumn{1}{|c|}{ Itens } & $\begin{array}{c}\text { Carga } \\
\text { fatorial }\end{array}$ \\
\hline $\begin{array}{l}\text { O enfrentamento de desafios na busca de } \\
\text { inovação é uma arte da docência. }\end{array}$ & 0,772 \\
\hline $\begin{array}{l}\text { O professor aberto para } \\
\text { interpretar e contextualizar a realidade } \\
\text { facilita o desenvolvimento da crítica nos } \\
\text { alunos. }\end{array}$ & 0,682 \\
\hline $\begin{array}{l}\text { O professor criativo desperta no aluno o } \\
\text { desejo de buscar sua criatividade. }\end{array}$ & 0,476 \\
\hline $\begin{array}{l}\text { O professor que desenvolve a capacidade } \\
\text { de resolução de problemas da docência } \\
\text { conquista a confiança dos alunos. }\end{array}$ & 0,474 \\
\hline $\begin{array}{l}\text { O entusiasmo do professor } \\
\text { contagia os alunos no processo ensino- } \\
\text { aprendizagem. }\end{array}$ & 0,453 \\
\hline
\end{tabular}

Fonte: Dados extraídos da pesquisa.

Nesse domínio, por ter agrupado três fatores (7, 8 e 9), definiu-se utilizar o "item total" do alfa de Cronbach em substituição à carga fatorial.

O domínio "Apoio pró-ativo à docência" apresenta itens que revelaram uma dimensão subjacente do pensamento dos professores quanto à busca de titulação como forma não só de diferenciar as universidades em relação às concorrentes, mas também visando ao autoaprendizado e à busca de novos conhecimentos como requisitos fundamentais para sua capacitação. Associado à visão generalista do professor, o uso de diferentes métodos de avaliação e o domínio de referências bibliográficas tendem a contribuir para que o professor enfrente melhor as dificuldades e limitações do aluno.

Para uma melhor operacionalização da escala e de seus domínios conceituais, os escores parciais (D1 a D5) e o global (Global) da escala foram definidos como a soma da pontuação obtida em cada um dos itens componentes do respectivo domínio, sendo o global a soma dos 34 itens que compõem o instrumento. 
Tabela 6: Domínio 5 - Apoio pró-ativo à docência

\begin{tabular}{|l|c|}
\hline \multicolumn{1}{|c|}{ Itens } & Item total \\
\hline $\begin{array}{l}\text { A titulação do corpo docente é um } \\
\text { fator que diferencia essa universidade } \\
\text { em relação às outras. }\end{array}$ & 0,829 \\
\hline $\begin{array}{l}\text { O autoaprendizado e a busca de novos } \\
\text { conhecimentos são requisitos para a } \\
\text { capacitação do docente. }\end{array}$ & 0,769 \\
\hline $\begin{array}{l}\text { A titulação do corpo docente melhora } \\
\text { a qualidade do ensino na universidade. }\end{array}$ & 0,766 \\
\hline $\begin{array}{l}\text { O uso de diferentes métodos de } \\
\text { avaliação permite acompanhar a } \\
\text { aprendizagem dos alunos. }\end{array}$ & 0,641 \\
\hline $\begin{array}{l}\text { A visão generalista do professor facilita } \\
\text { o desenvolvimento do olhar do aluno } \\
\text { para a realidade. }\end{array}$ & 0,587 \\
\hline $\begin{array}{l}\text { O domínio de referências bibliográficas } \\
\text { por parte do professor incentiva nos } \\
\text { alunos a pesquisa. }\end{array}$ & 0,475 \\
\hline $\begin{array}{l}\text { As dificuldades e limitações do aluno } \\
\text { devem ser foco de atenção dos } \\
\text { professores. }\end{array}$ & 0,346 \\
\hline
\end{tabular}

Fonte: Dados extraídos da pesquisa.

\section{Análise da confiabilidade e validade da escala}

A fim de avaliar a consistência interna dessa nova configuração da escala, foram calculados os coeficientes alfa para cada um desses novos domínios conceituais, obtendo índices favoráveis, conforme se apresenta na Tabela 7 .

Tabela 7: Coeficiente alfa de Cronbach

\begin{tabular}{|l|c|c|}
\hline \multicolumn{1}{|c|}{ Elementos da escala } & $\begin{array}{c}\text { Número de } \\
\text { itens }\end{array}$ & $\begin{array}{c}\text { Alfa de } \\
\text { Cronbach }\end{array}$ \\
\hline $\begin{array}{l}\text { Domínio 1 - Apoio } \\
\text { institucional }\end{array}$ & 8 & 0,8384 \\
\hline $\begin{array}{l}\text { Domínio 2 - Habilidade } \\
\text { interpessoal }\end{array}$ & 8 & 0,7896 \\
\hline $\begin{array}{l}\text { Domínio 3 - Capacidade } \\
\text { didático-pedagógica }\end{array}$ & 6 & 0,7357 \\
\hline $\begin{array}{l}\text { Domínio 4 - Abertura à } \\
\text { inovação }\end{array}$ & 7 & 0,7645 \\
\hline $\begin{array}{l}\text { Domínio 5 - Apoio à } \\
\text { docência }\end{array}$ & 5 & 0,6622 \\
\hline Entre os 5 domínios & 34 & 0,8767 \\
\hline Global - 34 itens da escala & \multicolumn{2}{|l}{} \\
\hline
\end{tabular}

Fonte: Dados extraídos da pesquisa.
Observa-se pela Tabela 7 que se apresentaram satisfatórios tanto os coeficientes alfa de cada domínio, quanto entre estes. Isso significa que não só os domínios individualmente explicam a escala, como também os domínios atuando conjuntamente mantêm a propriedade explicativa dela. Esses valores são suficientes para atestar a consistência interna da escala.

A confiabilidade é uma condição necessária, porém não suficiente. Precisa-se determinar a validade do instrumento (Kerlinger, 1980; Richardson, 1999). Existem três tipos de validade: de conteúdo, de critério e de constructo. De acordo com Kerlinger (idem), a validade de constructo provavelmente é a mais significativa e importante, motivo pelo qual optou-se por analisá-la neste estudo. Bowling (1997) considera duas dimensões da validade de constructo, que presume a confirmação de hipóteses sobre o comportamento correlacional (validade convergente) e sobre a capacidade discriminativa (validade discriminante) do instrumento.

Adotou-se o coeficiente de correlação ordinal de Spearman na análise da validade convergente devido à não normalidade das dimensões conceituais (o teste utilizado para avaliar se a distribuição era normal foi o de Kolmogorov-Smirnov). Não foi possível analisar a validade discriminante devido à ausência de um grupo-controle consistente.

Todos os coeficientes de Spearman se apresentaram estatisticamente significativos $(\mathrm{p}<0,05)$, variando de 0,206 a 0,646, garantindo com isso evidências de que a escala apresenta validade convergente. Em vista dos resultados obtidos, confere-se à escala alguma confiabilidade e validade convergente, atendendo, assim, ao segundo objetivo da pesquisa.

\section{Perfil dos respondentes - professores universitários}

De maneira geral, os respondentes apresentaram algumas características predominantes: homens $(65,2 \%)$, casados $(62,4 \%)$, profissionais da área de 
ciências humanas e sociais $(41,5 \%)$, cursando o mestrado (74,8\%), faixa etária de 31 a 40 anos $(41,8 \%)$, experiência de até cinco anos como docente $(29,4 \%)$, regime de trabalho horista $(53,2 \%)$, exercendo apenas a função de docência $(65,2 \%)$.

Esses resultados apontam que a maioria dos respondentes da amostra está em busca de titulação (mestrado), reforçando a posição de vários autores discutidos no referencial teórico de que as instituições têm valorizado sobremaneira esse aspecto. Prevalece um grupo de professores jovens, tanto em faixa etária, quanto em tempo de docência, contratados em regime de hora-aula, que fazem da profissão de docência sua única atividade profissional.

\section{Identificação de clusters de professores}

Adotou-se o K-Means Cluster, com indução de dois clusters, sobre as variáveis escalares idade, tempo de instituição e tempo de docência. Os clusters obtidos receberam a codificação 0 (composta por 185 casos) e 1 (composta por 97 casos).

Testes qui-quadrados foram realizados com a finalidade de analisar se havia associação estatisticamente significativa entre as variáveis não escalares de caracterização (sexo, estado civil, função exclusiva de docência ou não, titulação, regime de trabalho) e de clusters. Os resultados apontaram que os dois clusters não se diferenciam de forma estatisticamente significativa $(\mathrm{p}<0,05)$ quanto ao sexo, estado civil e função. A titulação demonstrou diferença estatisticamente significativa somente para mestres. Ou seja, o cluster 0 possui mais professores com titulação somente de mestrado.

No regime de trabalho, houve diferença estatisticamente significativa somente entre os percentuais do regime integral. Isso significa que o cluster 1 se compõe de mais professores nesse regime de trabalho. Para as variáveis de caracterização idade, tempo de docência e tempo na instituição e os escores da escala (domínios), foi realizado o teste de Mann-Whitney, cujos resultados se apresentam sintetizados na Tabela 8 .
Tabela 8 - Resultados do teste de Mann-Whitney

\begin{tabular}{|l|c|c|l|}
\hline \multicolumn{1}{|c|}{$\begin{array}{c}\text { Variáveis e } \\
\text { domínios }\end{array}$} & Agrupamentos & Média & Significância \\
\hline Idade & 0 & 34,3 & Significativo \\
\hline Tempo de & 0 & 7,0 & Significativo \\
docência & 1 & 21,6 & \\
\hline Tempo de & 0 & 4,2 & Significativo \\
instituição & 1 & 11,1 & \\
\hline Apoio & 0 & 32,1 & Não \\
institucional & 1 & 32,7 & significativo \\
\hline Habilidade & 0 & 43,6 & Significativo \\
interpessoal & 1 & 44,4 & \\
\hline Capacidade & 0 & 33,0 & Significativo \\
didático- & 1 & 33,2 & \\
pedagógica & 0 & 26,7 & Significativo \\
\hline Abertura à & 1 & 28,0 & \\
inovação & 0 & 34,7 & Não \\
\hline Apoio pró-ativo à & 1 & 35,4 & significativo \\
\hline docência & 0 & 170,0 & Não \\
\hline Global & 1 & 173,7 & significativo \\
\hline
\end{tabular}

Fonte: Dados extraídos da pesquisa.

A Tabela 8 mostra alguns resultados que permitem traçar características do cluster 1: são professores mais velhos, com média em torno de 51 anos, portanto bem acima do cluster 0 e da média geral (40 anos). Também são profissionais com elevada experiência na carreira docente - em torno de 21 anos, bem superior ao cluster 0 ( 7 anos) e à média geral (12 anos). Além disso, os professores do cluster 1 apresentam senioridade na instituição onde trabalham. Atuam há mais de 11 anos, ao passo que no cluster 0 se encontram professores com menos tempo de casa (4 anos). A média geral apresenta uma amostra de professores que trabalham nas instituições pesquisadas em torno de 6,5 anos. Esses dados, juntamente com os resultados do teste de qui-quadrado, revelaram que o cluster 1 se compõe de professores com mais idade, com ampla experiência em docência e "pratas da casa", que trabalham em regime de período integral.

O teste de Mann-Whitney, aplicado aos cinco domínios conceituais, revelou que os professores pertencentes ao cluster 1 valorizam mais as competências 
vinculadas à habilidade interpessoal, à capacidade didático-pedagógica e à abertura e inovação, ou seja, as competências centrais do estudo.

Os modelos estatísticos estudados até agora analisaram variáveis e dimensões de forma independente, ou seja, não consideraram as possíveis influências intervariáveis. A fim de superar essa limitação, realizou-se uma regressão logística entre as variáveis estudadas e os clusters. Recomenda-se o seu uso quando as variáveis independentes não atendem aos pressupostos subjacentes da análise multivariada (Hair et al., 2005, p. 78): normalidade, homoscedasticidade e linearidade, além do uso de variáveis não escalares. A variável dependente (clusters 0 e 1), por sua vez, é de natureza binária. A regressão logística é um tipo especial de regressão formulada para predizer e explicar uma variável categórica binária (idem, p. 246). Nesse modelo, a variável dependente é a probabilidade de o respondente estar no cluster 1 .

Os resultados da regressão logística sugeriram que somente as competências voltadas à abertura e inovação (domínio 4) parecem ter efeito real sobre a probabilidade referida e que tal efeito parece ser positivo, isto é, os professores que valorizam sobremaneira essas competências tendem a ter alta probabilidade de pertencer ao cluster 1 .

Quanto às variáveis de caracterização, os resultados indicaram que professores com mais idade, maior tempo de docência e na instituição tendem a ser classificados no cluster 1, confirmando os resultados já obtidos pelo teste do qui-quadrado. Esse cluster foi intitulado "Professores experientes", vis-à-vis o cluster 0 , nomeado "Professor iniciante", formado por docentes jovens, com menor tempo de vinculação à universidade e pouco tempo no exercício da docência, ou seja, um professor em processo de formação, confirmado pelo fato de os mestres estarem mais concentrados nesse cluster.

\section{Considerações finais}

A arena competitiva das universidades particulares está-se tornando cada vez mais agressiva, princi- palmente no estado de São Paulo. As instituições que buscam, além de sua mera sobrevivência, conquistar uma vantagem competitiva mais perene, oferecendo serviços e produtos que atendam e superem as necessidades de cada um de seus grupos de interesse (stakeholders), necessitam empreender ações planejadas para desenvolver sua capacidade competitiva. Práticas oportunistas de "caça aos talentos", atraindo professores titulados de outras instituições, não mais se constituem em uma forma sustentável de crescimento. Pode até proporcionar certo alívio por um tempo, mas o que se necessita é compreender os fundamentos que estão subjacentes ao entendimento do que é ser "competitivo".

O cenário educacional vem também exigindo inovações, formas diferenciadas para sobreviver num ambiente que requer transformações em meio à competitividade. $\mathrm{O}$ que as universidades têm feito para inovar? Os resultados demonstram que muito pouco tem sido feito para colocá-las no patamar de organizações que inovam.

$\mathrm{Na}$ pesquisa exploratória, as competências não foram vistas como fator de competitividade por parte da alta direção das universidades. Esta entende o conceito de competitividade relacionado a "estar construindo permanentemente, ganhar dos concorrentes, apresentar-se de maneira diferente e mostrar algo de inovador e de relevância para a sociedade".

Depreende-se que o ser competitivo aparece associado à ideia de mostrar-se atraente por meio de investimentos em infraestruturas modernas, inovadoras quanto às tecnologias de ensino, oferecendo produto de baixo custo e sabendo acompanhar as mudanças. Parece que a competitividade é um conceito mais extrínseco, reforçado pelo fato de o desenvolvimento de relevância acadêmica aparecer quase como uma necessidade ou justificativa isolada. Assim sendo, a capacidade intrínseca das instituições não se evidencia na fala dos dirigentes como elemento de competitividade. Então como as universidades poderão ser competitivas com essa perspectiva?

Esta pesquisa procurou reflexionar a necessidade de as universidades particulares entenderem que sua 
vantagem competitiva advém de um corpo docente competente, entendido como eixo e baliza. Essas competências, contudo, necessitam ser identificadas e desenvolvidas. Nesse sentido, não se entende que o "ser professor" é uma caminhada dirigida e conquistada pela mera disposição de realização que leva esse profissional a empreender esforços de autodesenvolvimento. É louvável, porém insuficiente.

As exigências apregoadas pelas instituições quanto ao processo de contratação de docentes para suas instituições fazem jus à necessidade de implantar ações focadas no desenvolvimento dessas competências fundamentais, para que o professor melhore seu desempenho e agregue valor às instituições e a si próprio. Portanto, o primeiro passo é desenvolver um instrumento para identificar a percepção de competências de docência, já que não se teve o propósito de avaliá-las. No entanto, construir um questionário constitui-se em verdadeiro desafio para o pesquisador, pois deve medir com exatidão aquilo que se propôs a fazer. Isso remete à necessidade de avaliar sua confiabilidade e validade, para que os resultados apresentem a qualidade necessária. A presente pesquisa teve esse fim, atestando, por meio de testes específicos, a confiabilidade interna e a validade de convergência da escala.

Os resultados da pesquisa quantitativa mostraram que o professor tem clareza quanto às competências requeridas para o exercício da docência. A análise fatorial e a análise de seus itens por meio do coeficiente alfa de Cronbach gerou cinco domínio conceituais, dos quais um refere-se ao apoio institucional e os demais estão relacionados a dimensões de competências. Buscou-se identificar dois clusters, a fim caracterizálos quanto às variáveis de caracterização e os domínios de competências, afinal nem todos os professores valorizam as mesmas competências.

As competências pesquisadas são oriundas principalmente da literatura, a qual postula a sua imprescindibilidade para o exercício efetivo da docência. São autores provenientes em sua maioria das áreas da educação e administração que pesquisam há anos sobre competência docente (Paquay et al., 2001;
Charlier, 2001; Machado, 2002; Thurler, 2002); a presente pesquisa validou essas competências para a amostra estudada. Entretanto, elas não se dão de forma equilibrada para todos os professores, conforme caracterização dos clusters.

Diferentes testes estatísticos, justificados quanto à adequação, foram realizados. Dois clusters foram encontrados; apresentaram algumas características essenciais: o cluster "Professores experientes" valoriza as competências voltadas à habilidade interpessoal, à capacidade didático-pedagógica e à abertura e inovação, apresentando-se com mais tempo na instituição, como docente em período integral e tendo mais idade.

O fato de os professores do cluster 0 , "Professores iniciantes", valorizarem menos essas mesmas competências requer uma reflexão. Esses docentes estão em busca de formação, por meio de conquista de titulação. Isso pode estar norteando prioritariamente seu foco de atenção, pois se constitui em fator essencial para sua empregabilidade nas universidades. Por sua vez, os professores experientes, já mais estabilizados em suas carreiras, passam a vivenciar o ato da docência em si, amparados por vasta experiência até mesmo em pesquisa, pois muitos são professores em regime integral, voltados portanto à pesquisa e a docência.

Os professores iniciantes, com foco voltado para a busca da titulação, podem não entender o que as universidades esperam deles e, sobretudo, quais competências necessitam desenvolver para conquistar o patamar dos experientes. Então se questiona: $A s$ universidades têm revelado tais competências e como as valorizam?

As universidades necessitam situar os iniciantes, com o intuito de explicitar quais competências são necessárias ao exercício da docência e, assim, implementar suas ações para conquistar competitividade e elevar a qualidade e a excelência do ensino. A titulação não é o único requisito na formação de competência. Ela legitima a empregabilidade do professor no âmbito das universidades, mas não o habilita para o que Machado (2002) considera competência docente: $a$ pessoalidade, o âmbito e a mobilização. 
Os resultados da pesquisa revelaram competências que são ressaltadas e valorizadas na literatura, como as apontadas a seguir:

1) a necessidade de o professor buscar a ação interdisciplinar para estimular a criticidade e integrar ensino com pesquisa (Castanho, 2000);

2) a mudança de um professor "ensinante" para o professor "que está com" o aluno, para que ele possa aprender (Masetto, 2001);

3) o despertar da criatividade e da comunicação para interpretar a realidade; a busca de flexibilidade para acompanhar as mudanças e promover um ensino de qualidade para o saber fazer, $o$ saber pensar, o saber ser, criando a mentalidade do aprender a aprender (Moraes, 1997);

4) organização e direção de situações de aprendizagem, administrando suas progressões, concebendo e fazendo evoluir os dispositivos de diferenciação, envolvendo alunos para trabalhar em equipe, utilizando novas tecnologias, enfrentando deveres e dilemas éticos e administrar a própria formação (Perrenoud, 2000);

5) a assunção, como eixo de suas ações, do aprendizado para colaborar com a transformação do aluno (Bélair, 2001); e

6) a preparação dos alunos contra os perigos da fragmentação, construindo uma identidade mais integrada por meio de pressupostos teórico-práticos, para responder às questões pessoais e sociais (Hass, 1998).

Esses achados da pesquisa e as reflexões realizadas neste artigo se perpetuam porque as competências identificadas não são específicas do professor presencial, uma vez que elas podem ser pensadas para o professor que dirige o ensino a distância. Salmon (2002), por exemplo, oferece sugestões práticas para professores iniciantes e professores experientes para ministrarem ensino a distância. Propõe um modelo five-step, que reflete progressão positiva na qualidade e intensidade de interação entre alunos e entre alunos e seus professores. O papel do professor online, como tem sido chamado, é multidimensional e muda conforme os diferentes estágios, em função das necessidades dos alunos e das circunstâncias de cada curso. Dessa forma, o professor tem que usar do discernimento sobre as suas estratégias de ensino, para atender efetivamente às necessidades de aprendizagem dos alunos. Salmon chama a atenção para algumas das competências profundamente discutidas no texto, fruto dos resultados da pesquisa, ressaltando que o primeiro step (doravante será denominado etapa) se refere ao acesso à motivação, que visa ajudar os novos alunos a se familiarizar com o ambiente on-line para desenvolver suas atividades educativas. A segunda etapa envolve a socialização on-line, cujo objetivo é a construção do alicerce para uma comunidade que precisa cultivar confiança entre os alunos e que visa ao treinamento para trabalhos em grupo. A outra etapa envereda para a necessidade de intercâmbio de informações, que propiciará oportunidade para explorar e partilhar conhecimentos nas discussões de classe. A quarta etapa refere-se à construção do conhecimento, que de certa forma marca o desenvolvimento das habilidades, do saber pensar e de se tornarem alunos independentes.

Vale ressaltar que a pesquisa em pauta aponta que uma das competências mais valorizadas pelos respondentes se refere-se à competência do professor que contribui para tornar o aluno independente e, assim, consolidar sua aprendizagem. E, por fim, a etapa do desenvolvimento de novas habilidades cognitivas, que permitem que os alunos aprendam a acompanhar e avaliar o seu pensamento, a apropriarem-se de suas experiências pessoais e fazer uso de sua aprendizagem.

Assim, fica claro que as competências discutidas neste artigo continuam sendo imprescindíveis e centrais não apenas para professores presenciais, mas também para aqueles que atuam em ambientes virtuais, o que sugere e estimula o desenvolvimento de novas pesquisas.

\section{Referências bibliográficas}

ALTET, Marguerite. As competências do professor profissional: entre conhecimentos, esquemas de ação e adaptação, saber analisar. 
In: PAQUAY, Léopold et al. Formando professores profissionais: quais estratégias? Quais competências? Porto Alegre: Artmed, 2001.

BAILLAUQUÈS, Simone. Trabalho das representações na formação dos professores. In: PAQUAY, Léopold et al. Formando professores profissionais: quais estratégias? Quais competências? Porto Alegre: Artmed, 2001. p. 37-54.

BALBACHEVSK, Elizabeth. A profissão acadêmica no Brasil: as múltiplas facetas do nosso sistema de ensino superior. São Paulo: FUNADESP, 1999. p. 169.

BÉLAIR, Louise. A formação para a complexidade do ofício de professor. In: PAQUAY, Léopold et al. Formando professores profissionais: quais estratégias? Quais competências? Porto Alegre: Artmed, 2001. p. 55-64.

BOWLING, Ann. Measuring health: a review of quality of life measurement seals. 2. ed. Buckingham: Open University Press, 1997. p. 11.

CASTANHO, Maria Eugenia. A criatividade na sala de aula universitária. In: VEIGA, Ilma Passos; CASTANHO, Maria Eugenia (Org.). Pedagogia universitária: a aula em foco. Campinas: Papirus, 2000.

CHARLIER, Évelyne. Formar professores profissionais para uma formação contínua articulada à prática. In: PAQUAY, Léopold et al. Formando professores profissionais: quais estratégias? Quais competências? Porto Alegre: Artmed, 2001. p. 85-102.

D’AMBRÓSIO, Ubiratan. Os novos paradigmas e seus reflexos na destruição de certos mitos hoje prevalentes na educação. Educação Brasileira, v. 17, n. 34, jan./jun. 1995.

DE SORDI, Mara Regina Lemes. Avaliação da aprendizagem universitária em tempos de mudanças: a inovação ao alcance do educador comprometido. In: VEIGA, Ilma Passos; CASTANHO, Maria Eugenia (Org.). Pedagogia universitária: a aula em foco. Campinas: Papirus, 2000.

DUTRA, Joel. Gestão de pessoas com base em competências. In: DUTRA, Joel. (Org.). Gestão por competências. São Paulo: Gente, 2001.

FAINGOLD, Nadine. De estágio a especialista: construir as competências profissionais. In: PAQUAY, Léopold et al. Formando professores profissionais: quais estratégias? Quais competências? Porto Alegre: Artmed, 2001.

FLEURY, Afonso; FLEURY, Maria Tereza Leme. Estratégias empresariais e formação de competências: um quebra-cabeça caleidoscópico da indústria brasileira. São Paulo: Atlas, 2000.
FREIRE, Paulo. Pedagogia da autonomia: saberes necessários à prática educativa. São Paulo: Paz e Terra, 1997.

HAAS, Célia Maria. O exercício possível da docência interdisciplinar nas instituições privadas de ensino superior. Revista UNICSUL, v. 3, n. 4, p. 164-171, ago. 1998.

HAIR, Joseph F. et al. Análise multivariada de dados. 5. ed. Porto Alegre: Bookman, 2005.

KERLINGER, Fred N. Metodologia da pesquisa em ciências sociais: um tratamento conceitual. São Paulo: EPU-EDUSP, 1980.

KINCHELOE, Joe. L. A formação do professor como compromisso político: mapeando o pós-moderno. Porto Alegre: Artes Médicas, 1997.

KULLOK, Maisa. G. B. Um novo paradigma na formação de professores para o próximo milênio. Revista UNICSUL, v. 3, n. 4, p. 6-24, ago. 1998.

MACHADO, Nilson José. Sobre a ideia de competência. In: PERRENOUD, Philippe; THURLER, Monica G. As competências para ensinar no século XXI: a formação dos professores e o desafio da avaliação. Porto Alegre: Artmed, 2002. p. 137-155.

MASETTO, Marcos. T. Atividades pedagógicas no cotidiano da sala de aula universitária: temas e textos em metodologia do ensino superior. Campinas: Papirus, 2001.

MORAES, Ana S. F. A universidade brasileira no final do século XX e o mercado de trabalho. Educação Brasileira, v. 19, n. 38 , p. 73-91, jan./jul. 1997.

MORGADO, L. O papel do professor em contextos de ensino online: problemas e virtualidades. In: Discursos, III série, n. especial, p. 125-138, 2001.

NISKIER, Arnaldo. $L D B$ : a nova lei de educação. Rio de Janeiro: Consultor, 1998.

PAQUAY, Léopold et al. Formando professores profissionais: quais estratégias? Quais competências? Porto Alegre: Artmed, 2001.

PERRENOUD, Philippe. Dez novas competências para ensinar. Porto Alegre: Artes Médicas, 2000.

RICHARDSON, Roberto J. Pesquisa social: métodos e técnicas. São Paulo: Atlas, 1999.

SALMON, Gilly. E-tivities: the key to active on-line learning. London: Kogan Page, 2002.

SAMPAIO, Helena Maria. O setor privado no ensino superior no Brasil. Tese (Doutorado em Ciências Políticas) - Faculdade de Filosofia, Letras e Ciências das Humanidades, Universidade de São Paulo, São Paulo, 1998.

SCOZ, Beatriz. J. A psicopedagogia na visão multidisciplinar e 
transdisciplinar. Revista Psicopedagogia, UNICAMP, v. 15, n. 39, p. 22-27, 1996.

SHOR, Ira; FREIRE, Paulo. Medo e ousadia: o cotidiano do professor. Rio de Janeiro: Paz e Terra, 1986.

SMITH, David. K. Fazendo a mudança acontecer. São Paulo: Campus, 1997.

THURLER, Monica. G. O desenvolvimento profissional dos professores: novos paradigmas, novas práticas. In: PERRENOUD, Philippe; THURLER, Monica. G. As competências para ensinar no século XXI: a formação dos professores e o desafio da avaliação. Porto Alegre: Artmed, 2002.

TRAMONTIN, Raulino. Ensino superior: uma agenda para repensar seu desenvolvimento. Educação Brasileira, v. 18, n. 36, p. 35-62, jan./jul. 1998.

TRIPODI, Tony; FELLIN, Phillip; MAYER, Henry. Análise da pesquisa social. Rio de Janeiro: Francisco Alves, 1981.

VASCONCELOS, Maria Lucia M. Carvalho. A formação do professor de terceiro grau. São Paulo: Pioneira, 1996.

WAGNER, Marie-Cécile. Pratique du micro-enseignement, une méthode souple de formation des enseignants. Bruxelles: De Boeck, 1988.

VÂNIA MARIA JORGE NASSIF, doutora em administração de empresas pela Universidade Presbiteriana Mackenzie, é professora do Centro de Ciências Sociais e Aplicadas e coordenadora do Núcleo de Empreendedorismo e Desenvolvimento Empresarial da mesma universidade. É também professora colaboradora do Programa de Mestrado em Administração da Faculdade Campo Limpo Paulista. Publicações recentes: em coautoria com GHOBRIL, Alexandre. N.; AMARAL, Derly. J. Empreendedorismo por necessidade: o desemprego como impulsionador da criação de novos negócios no Brasil (Pensamento \& Realidade, v. 24, n. 1, p. 143-168, maio 2009); em coautoria com AMARAL, Derly J. et al. Formação empreendedora: aspectos convergentes e divergentes sob a ótica de alunos, professores, pais e empreendedores (Revista ANGRAD, v. 10, n. 2, p. 73-96, abr./maio/jun. 2009); em coautoria com ARMOND, Álvaro C. A liderança como elemento do comportamento empreendedor: um estudo exploratório (Revista de
Administração Mackenzie, v. 10, p. 77-106, 2009). Pesquisa em andamento: "Educação empreendedora e comportamento empreendedor”.E-mail:vania.nassif@uol.com.br

DARCY MITIKO MORI HANASHIRO, doutora em administração de empresas pela Universidade de São Paulo, é professora do Centro de Ciências Sociais e Aplicadas e coordenadora do Programa de Pós-Graduação de Administração e do Núcleo de Liderança e Diversidade Cultural da Universidade Presbiteriana Mackenzie. Publicações recentes: em coautoria com SILVEIRA, Nereida S. P. Similaridade e dissimilaridade entre superiores e subordinados e suas implicações para a qualidade da relação didática (RAC Eletrônica, v. 13, n. 1, p. 117-135, jan./mar. 2009); organizadora de Gestão do fator humano: uma visão baseada em stakeholders (São Paulo: Saraiva, 2008); em coautoria com NASSIF, Vânia M. J. Competências de professores: um fator competitivo (Revista Brasileira de Gestão de Negócios, v. 8, n. 1, p. 45-56, jan./abr. 2006). Pesquisa em desenvolvimento: "Diversidade e inclusão nas organizações: por uma abordagem culturalmente contextualizada para a realidade brasileira". E-mail: darcyhanashiro@gmail.com

ROSANE RIVERA TORRES, doutora em administração de empresas pela Universidade de São Paulo, é professora da mesma universidade. Publicações recentes: em coautoria com GOUVÊA, Maria Aparecida. Percepção da reputação, credibilidade e imagem de marca dos cursos de mestrado e doutorado em administração (Revista de Economia e Administração, v. 6, n. 4, p. 485-519, out./dez. 2007); em coautoria com GUIMARÃES, Cesar Martins. A hipótese conjunta do CAPM e mercado eficiente (Revista Faces, Belo Horizonte, v. 6, n. 2, p. 72-87, maio/jul. 2006). Pesquisa em andamento: "Avaliação do uso da análise fatorial exploratória, confirmatória e modelagem em equações estruturais em periódicos nacionais nível A na área de Administração de Empresas”. E-mail: rtorres@terra.com.br 
individual, acesso obtido mediante competição acirrada, na qual as responsabilidades são privatizadas. Do ponto de vista teórico, operamos sob a inspiração dos estudos do filósofo Michel Foucault.

Palavras-chave: educação; conquista; governamentalidade; Vestibular/ZH; Michel Foucault

The productive game of educabilitygovernmentality in the constitution of university subjects

This paper is based on recent research which seeks to understand some of the ways in which university subjects are at present constituted drawing upon the University Entrance (Vestibular) sections in the Zero Hora newspaper. We consider that the production of school curricula emerges from a network of relations of educability and governmentality. Thus, we understand that the statements which appear in the print-based media produce meanings for the production of the subjects as well as for contemporary school practices, resulting perhaps in the elaboration of a 'curriculum of conquest'. This curricular configuration leads to individualisation and to making these subjects accountable, mediated by the production of a consumerist agenda, which places access to university knowledge in the individual field, obtained through tough competition in which responsibilities are private. From the theoretical standpoint our analysis is inspired by the studies of the philosopher Michel Foucault.

Key words: education; conquest; governmentality; University Entrance Sections of the newspaper Zero Hora (Vestibular/ZH); Michel Foucault

El juego productivo de la relación educacional gubernamental en la constitución de sujetos universitarios El artículo resulta de una pesquisa reciente que buscaba comprender algunos de los modos por los cuales los sujetos universitarios son constituidos en la contemporaneidad, tomando como materialidad los cuadernos de la Selectividad/ZH. Consideramos que la producción de los currículos escolares emerge de un argumento de relaciones educacionales y gubernamentales. De esta forma, entendemos que los enunciados emergentes de ese medio de comunicación impreso producen sentidos a la producción de los sujetos y también a las prácticas escolares contemporáneas, a lo que tal vez encamine la producción de un "currículo de la conquista". Tal configuración conduce a la individualización y a la responsabilización de sujetos, intermediados por la producción de una norma de consumo que define el acceso al saber universitario en el campo individual, acceso obtenido por medio de competición incitada, en la cual las responsabilidades son privatizadas. Del punto de vista teórico, operamos sobre la inspiración de los estudios del filósofo Michel Foucault.

Palabras clave: educación; conquista; gubernamental; Selectividad/ZH; Michel Foucault

Vânia Maria Jorge Nassif, Darcy Mitiko Mori Hanashiro e Rosane Rivera Torres

\section{Fatores que influenciam na} percepção das competências para o exercício da docência

Este artigo analisa as competências requeridas para docência acadêmica em relação às características demográficas e funcionais de docentes universitários. A partir da resposta de 282 docentes ao questionário aplicado em uma amostra de conveniência, realizou-se análise de confiabilidade e validação de constructo, gerando escala para avaliar a percepção das referidas competências. Por meio de técnicas multivariadas, dois grupos de docentes foram identificados: professor experiente e professor iniciante. $\mathrm{O}$ primeiro, formado por profissionais com idade mais elevada e mais tempo de docência e permanência na instituição, valoriza sobremaneira as competências relativas à habilidade interpessoal, à capacidade didáticopedagógica e abertura à inovação, quando comparado ao segundo grupo. Os professores iniciantes, com menor tempo de vinculação à universidade $\mathrm{e}$ pouco tempo no exercício da docência, têm o foco voltado para a obtenção de titulação, demonstrando não entender o que as universidades esperam deles e, sobretudo, quais competências necessitam desenvolver para conquistar o patamar dos experientes.

Palavras-chave: competência de docentes; escala de percepção de competência de docentes; competitividade da universidade privada.

\section{Factors which influence the} perception of competences for the teaching profession

This article analyses the competences required for academic teaching in relation to the demographic and functional characteristics of university teachers. Based on replies from 282 lecturers to the questionnaire applied in a sample of convenience, an analysis of construct reliability and validation was carried out, generating a scale for evaluating the perception of those competences. By means of multivariable techniques, two groups of lecturers were identified: experienced and new lecturers. The first, made up of older and more experienced lecturers, values above all competences related to interpersonal skills, didacticpedagogical capacity and openness to innovation when compared to the second group. The new professionals, with less time in the University and less teaching experience, were more focused on obtaining titles. They revealed a lack of understanding of what universities expect from them and, above all, what competences they need to develop in order to reach the level of experienced lecturers. 
Key words: teaching competences; scale of perception of teaching competences; competitiveness of the private university.

Factores que influencian en la percepción de las competencias para el ejercicio de la docencia

Este artículo analiza las competencias solicitadas para la docencia académica en relación a las características demográficas y funcionales de docentes universitarios. Partiendo de las respuestas de 282 docentes al cuestionario aplicado en una muestra de conveniencia, se realizó un análisis de confiabilidad y validad de constructor, generando una escala para evaluar la percepción de las referidas competencias. A través de técnicas multivariadas, dos grupos de docentes fueron identificados: profesor experimentado $y$ profesor iniciante. $E l$ primero, formado por profesionales con edad más elevada y más tiempo de docencia y permanencia en la institución, valoriza sobremanera las competencias relativas a la habilidad interpersonal, a la capacidad didáctica pedagógica y su abertura a la innovación, cuando comparado al segundo grupo. Los Profesores Iniciantes, con menor tiempo de vinculación a la universidad y poco tiempo en el ejercicio de la docencia, tienen el enfoque direccionado para la obtención de títulos; demostrando no entender lo que las universidades esperan de ellos y, sobretodo, cuales competencias son necesarias desenvolver para conquistar el nivel de los profesores experimentados.

Palabras claves: competencia de los docentes; escala de percepción de competencia de los docentes; competitividad de la universidad privada.
Dermeval Saviani

\section{Sistema Nacional de Educação articulado ao Plano Nacional de Educação}

Versando sobre o tema central da Conferência Nacional de Educação (CONAE), realizada em Brasília de 28 de março a $1^{\circ}$ de abril de 2010 , o texto trata do conceito de Sistema Nacional de Educação em articulação com o Plano Nacional de Educação. Para tanto, após indicar os usos básicos do conceito de sistema, aborda a questão do Sistema Nacional de Educação explorando, em especial, o problema federativo para mostrar a plena compatibilidade da organização do Sistema Nacional de Educação com o regime federativo. Na sequência, aborda o significado histórico do Plano Nacional de Educação mostrando que o plano é uma exigência do sistema, uma vez que a educação sistematizada implica a ação planejada. Assim sendo, o Plano Nacional de Educação constitui o meio pelo qual se pode aferir o grau em que o Sistema Nacional de Educação está cumprindo as metas e objetivos que lhe cabe atingir.

Palavras-chave: Sistema Nacional de Educação; plano nacional de educação; educação brasileira; política educacional

National System of Education articulated with the National Plan of Education

This text which discusses the central theme of the National Conference on Education (CONAE), held in Brasilia from $28^{\text {th }}$ March to $1^{\text {st }}$ April 2010, deals with the concept of a National System of Education in articulation with the National Plan of Education. To that end, after pointing to the basic uses of the concept of system, it discusses the question of the National System of Education exploring the federative question in order to reveal the complete compatibility of the organization of the National System of Education with the federative regime. Thereafter, it deals with the historical meaning of the National Plan of Education demonstrating that the plan is a demand of the system, since planned action is implicit in systematized education. Thus the National Plan of Education is fulfilling those goals and objectives for which it is responsible.

Key words: national system of education, national plan of education, Brazilian education, educational policy

\section{Sistema Nacional de Educación articulado al Plano Nacional de Educación}

Versando sobre el tema central de la Conferencia Nacional de Educación (CONAE), realizada en Brasilia del 28 de marzo al $1^{\circ}$ de abril de 2010, el texto trata del concepto del Sistema Nacional de Educación en articulación con el Plano Nacional de Educación. Por tanto, después de indicar los usos básicos del concepto del sistema, aborda la cuestión del Sistema Nacional de Educación explorando, en especial, el problema federativo para mostrar la plena compatibilidad de la organización del Sistema Nacional de Educación con el régimen federativo. En la secuencia, aborda el significado histórico del Plano Nacional de Educación mostrando que el plano es una exigencia del sistema, una vez que la educación sistematizada envuelve la acción planeada. Así pues, el Plano Nacional de Educación constituye el medio por el cual se puede comparar el grado en que el Sistema Nacional de Educación está cumpliendo las metas y objetivos que le corresponde alcanzar.

Palabras clave: sistema nacional de educación; plano nacional de educación; educación brasileña; política de la educación 